\title{
According to Their Emotional Plots, the Iliad is Most Likely Tragic While the Odyssey Is Not
}

\author{
By Cynthia Whissell*
}

\begin{abstract}
The words of Kline's English translations of the Iliad and the Odyssey were scored in terms of their emotional connotations with the Dictionary of Affect in Language (Whissell 2009). Plots of the two epics were modeled in terms of variations in word unpleasantness (which was assumed to represent misfortune) across time. At the overall level, words in the Iliad were significantly more unpleasant (unfortunate), active, and concrete than those in the Odyssey. The plot of the Iliad was described in terms of two cycles of action, and the plot of the Odyssey in terms of three cycles. The Iliad satisfied Aristotle's requirements of a tragedy in terms of misfortune (unfortunate overall tone, movement from lesser to greater misfortune, unfortunate conclusion) while the Odyssey did not. In their emotional differences, the epics matched differences between Shakespearean tragedies (Iliad) and comedies (Odyssey) described in previous research.
\end{abstract}

Keywords: Emotion, Iliad, Odyssey, Plot

The Iliad and the Odyssey are two ancient Greek poetic epics. A brief outline of the contents of the two epics is provided in Tables 1 and 2.

Table 1. Two Emotional Cycles in the Plot of the Iliad

Preceding events: The Trojan War is being fought by the Achaeans (headed by Agamemnon) and the Trojans (headed by Hector) because a prince of Troy (Paris) absconded with Helen, wife of Menelaus, an Achaean. The war takes place at and around Troy.

\begin{tabular}{l|l} 
Cycle & Themes \\
\hline 1st cycle Books 1-9 & Achilles furious, Agamemnon deluded, the Achaeans attack and lose
\end{tabular}

Agamemnon has to give up one of his war prizes (a female slave) because the god Apollo has visited a plague on the Achaean troops. When this slave is reclaimed, Agamemnon seizes the female slave of Achilles, a fellow Achaean, which infuriates Achilles. Achilles refuses to participate further in the war, but asks his mother (a demi-goddess) to wring a promise of vengeance from Zeus. Zeus misleads Agamemnon into thinking that an attack by the Achaeans will be successful. Agamemnon launches the attack. The war seems to be going well for the Achaeans, but Zeus, remembering his promise, instructs the gods who have been helping both sides not to interfere. The Achaeans are in danger of losing the war; Agamemnon tries to make peace with Achilles, but fails. The minor crisis point of the first cycle is in Book 3 where Menelaus and Paris duel.

Main cycle Books 10-24 $\quad$ Patroclus dies, Achilles seeks vengeance, the Achaeans win a major battle

Various Trojan attacks meet with success, Hera seduces Zeus so that while he sleeps other gods can help the Achaeans; Zeus awakens. Apollo helps the Trojans. Achilles' dear friend Patroclus joins the battle wearing Achilles' armour in an attempt to rally the Achaeans. He succeeds but he is killed by Hector. Patroclus' body is recovered for burial. Achilles rejoins the war in great fury, after reconciling with Agamemnon. Achilles fights and kills Hector. The Achaeans are in the ascendant again. Hector's body is ransomed by his father and buried. The climax of this cycle (which is also the most unpleasant point in the whole epic) takes place in Book 15 where the forces of the Trojans and the Achaeans (and their aligned gods) battle furiously with no clear winner.

Succeeding events: The Achaeans win the Trojan War thanks to the trickery of Odysseus. Achilles dies during the war.

${ }^{*}$ Chair, Psychology Department, Laurentian University, Canada. 
Table 2. Three Emotional Cycles in the Plot of the Odyssey

Preceding events: The Trojan War has ended; many have died. While most of the surviving Achaeans have returned to their kingdoms, Odysseus, the ruler of Ithaca, has been "lost in transit". \begin{tabular}{|l|l|}
\hline Cycle & Themes \\
\hline
\end{tabular}

\begin{tabular}{l|l} 
1st cycle Books 1-7 & Athena promotes Odysseus's return
\end{tabular}

Athena contacts Telemachus, Odysseus's son, and also asks the gods to help Odysseus return home. Telemachus disputes with the suitors who have been bedeviling his mother, Penelope, in an attempt to take over Odysseus' house and wealth. Zeus and the gods work to free Odysseus from Calypso, a nymph who loves him and has imprisoned him on her island; Poseidon, father of the cyclops, causes a shipwreck but Odysseus reaches shore safely. Odysseus is received hospitably by Nausicaa, princess of Phaeacia. The minor crisis point of the first cycle occurs in Book 4 where Helen and Menelaus talk to Telemachus about his father and about the Trojan War.

\begin{tabular}{l|l} 
2nd cycle Books 8-16 & Odysseus relates his adventures, returns to Ithaca
\end{tabular}

An unrecognized Odysseus participates in celebratory games and wins; Demodocus, the bard, sings of the gods and of the Trojan War. Odysseus tells the tale of his travels and his escapes. He tells of offering blood and the visits of ghosts, including those of Achilles and Agamemnon. He describes losing men at Scylla and Charybdis, and more men after that because they broke an oath and were punished by Zeus. Odysseus travels back to Ithaca, and meets Athene in disguise; he himself is disguised by the goddess who promises to help him. Eumaeus, the swineherd, waits faithfully for Odysseus' return; Eumaeus, Odysseus and Telemachus meet, make plans, send messages to Penelope. The minor crisis point of the second cycle occurs in Book 12 where Odysseus relates the loss of his men during his journey.

Main cycle Books 17-24 1 Odysseus slays the suitors, reunites with Penelope

Odysseus arrives at the palace in disguise, he interacts with the suitors but avoids Penelope. Tensions build between Odysseus and the suitors; Telemachus tries to keep things quiet. Penelope talks to the unrecognized Odysseus; she sets an archery challenge for the suitors (a challenge that only Odysseus could win), agreeing to marry the man who meets the challenge. There are omens from the gods favourable to Odysseus, but tensions continue to build. Odysseus uses his bow to slay all the suitors and he also executes some of Penelope's servingwomen who have been disloyal. Penelope talks with Odysseus and becomes convinced of who he is. Agamemnon and Amphimedon visit from the underworld; Odysseus meets with his old father; the suitors' parents threaten revenge but Athene brokers peace in Ithaca. The climax of the third cycle is the most unpleasant point of the entire epic; it occurs in Book 21 where the challenge of the bow begins. In Book 22 Odysseus slays the suitors.

The epics are connected by more than the language in which they were written. The Iliad describes part of the Trojan War and the Odyssey the aftermath of this war. They do not refer directly to one another, but in the Odyssey characters from the Iliad (including some visiting from the realm of the dead, such as Achilles) discuss the Trojan War and its outcomes. The written form of the epics is assumed to have appeared sometime in the 8th century BCE. Although both poems have historically been attributed to a blind poet named "Homer", research focusing on language patterns highlights differences between them and supports a conclusion of different authorship (Martindale and Tuffin 1996). It is possible that "Homer" was not a single individual, but rather that the poems were "the product of a long tradition of oral poetry" which gelled over several generations (Rutherford 1993). Whatever their origins, the epics had crystallized into written form before the time of Aristotle (384-322 BCE; 1924) who heaped praise upon them and their assumed author (Homer) in his Poetics.

The question addressed by this research article is "What form best describes the Iliad and the Odyssey? Are the epics comedies or tragedies?" Aristotle (1924, Part IV) classified them as tragic epics, but both ancient and recent viewpoints 
have disagreed with this conclusion. Hall (2008) studied theatrical presentations of the Odyssey and concluded that this epic can only be dragged into the definition of tragedy by doing considerable violence to the "psyche, politics, and motivation" of its protagonist (pp. 518, 519). She noted that even in ancient Greece, the Odyssey was received as a success story and was read as being positive rather than negative in tone (p. 500).

A congruent - but not identical—reading of the Odyssey is offered by Sutton (1974) who classifies it as an original of the "satyr plays" where the hero meets and then overcomes the fantastic villain in a drama aimed at comic relief. Sutton contrasts the pessimistic tone of the Iliad to the idealistic tone of the Odyssey, and the distant hero of the first epic to the hero of the second who is more like "an idealized portrait of ourselves" (p. 179). In a similar vein, Rutherford (1993) suggests that ancient audiences seemed to regard the Iliad - but not the Odysseyas a tragedy. With its "happy resolution", the latter epic was classified as a melodrama or comedy (p. 41). Dean (1976) points out that many critics have appreciated the comic elements of the Odyssey, but he argues instead for its status as a romance. According to this author, prominent motifs of romances include "marvel, risk, triumphant adventure, ... idealized male-female relationships,... the wandering journey toward 'home',... flourishing digressions,... [and] a final reunion" (Dean 1976: 229). These motifs are very evident in the Odyssey. One thing that comedies, satyr plays, and romances have in common is a "happy ending" where the protagonist is rewarded for his efforts and his antagonists are punished for their sins.

While readers and critics have been reluctant to classify the Odyssey as a tragic epic, they have been quite comfortable with Aristotle's placement of the Iliad in this category (e.g., Rutherford 1982, Tait 1943). It is possible that the Iliad is tragic in form while the Odyssey is not. The validity of this assignment depends, of course, on the definition of the forms. Aristotle insisted that tragic dramas (and good epic tragedies) be imitative of life, that they deal with a superior class of being rather than the everyday man, that they have a unity of plot, and that they depict a movement from good to bad fortune by means of recognition, and suffering ${ }^{1}$. Achilles's wrath, the resulting death of Patroclus, and the eventual victory of the Achaeans are the unified theme of the Iliad. Fortune moves from good to bad (or at least bad to worse) as a result of Achilles' actions, and he eventually recognizes his role in Patroclus' death. However, the Achaean victories near the end of the epic, the funeral games and celebrations for Patroclus, and the understanding reached with Hector's father so he could bury his son, are anticlimactic and do not fit the pattern of continued negativity. Aristotle allows for changes such as these in complex plots.

In order to appreciate the way in which fortune changes across each epic, it was decided to examine the emotional connotations of their words, employing relatively objective techniques to classify the epics as tragedies or comedies. Two presumptions underlie this approach. The first is that words have measurable

\footnotetext{
${ }^{1}$ Several additional Aristotelean criteria such as imitation, recognition, and reversal are not discussed here because they must be inferred - they cannot be measured by the techniques employed in this research.
} 
emotional connotations and the second that these connotations can be employed to represent fortune and display the manner in which it changes across a work. These presumptions are addressed by the use of the Dictionary of Affect in Language (Whissell 2009) as a measurement tool. The Dictionary includes scores for the emotional connotations of thousands of English words. Scores were obtained by asking volunteers to rate the connotations of each word along the dimensions of pleasantness, activation, and concreteness or imagery. As illustrated below, Dictionary scores representing word pleasantness can be employed to describe the positivity (or negativity) of passages. Highly pleasant language is assumed to represent a pervading sense of fortune in a segment of text and highly unpleasant language predominant misfortune.

\section{Employing the Dictionary of Affect to Describe Fluctuations in Fortune}

The manner in which pleasantness can be used to describe fluctuations in fortune is exemplified here with the help of the lyrics of the popular folk song Puff the Magic Dragon (Peter, Paul and Mary n.d.) After repetitions of the chorus were removed, the song was divided into four verses of four lines apiece. Every word in the lyrics was then matched to the Dictionary of Affect with the help of a computer program. For $82 \%$ of the 163 words, it was possible to find a match and an associated pleasantness score. For example, on a scale of approximately 120 points, the word magic had a pleasantness score of 99 and the word loved a pleasantness score of 119. At the unpleasant end of the dimension, the word grey had a score of 6.5 and the word fell a score of 24.72. All matched words in each verse were employed to produce a verse average $(47.35,46.02,44.29$, and 46.13, respectively). Because tragedies are assumed to climax in a misfortune (low pleasantness) pleasantness scores were inverted and then plotted in Figure 1. Each point in the figure represents the degree of misfortune behind the words in the verse. A clear pattern is evident in the figure. Misfortune rises to a climax in the third verse and then falls somewhat. The contents of each verse are summarized in the figure, which suggests that the climax of the song takes place in the verse where Jackie, the little boy who has grown up, abandons Puff, the dragon. The happiest verse is the first one. After this verse, the lyrics move towards greater misfortune, until Puff retires from the scene in an anti-climactic verse of moderate misfortune. 
Figure 1. The Plot of Puff (The Magic Dragon) Described on the Basis of Variations in Unpleasantness or Misfortune across Verses

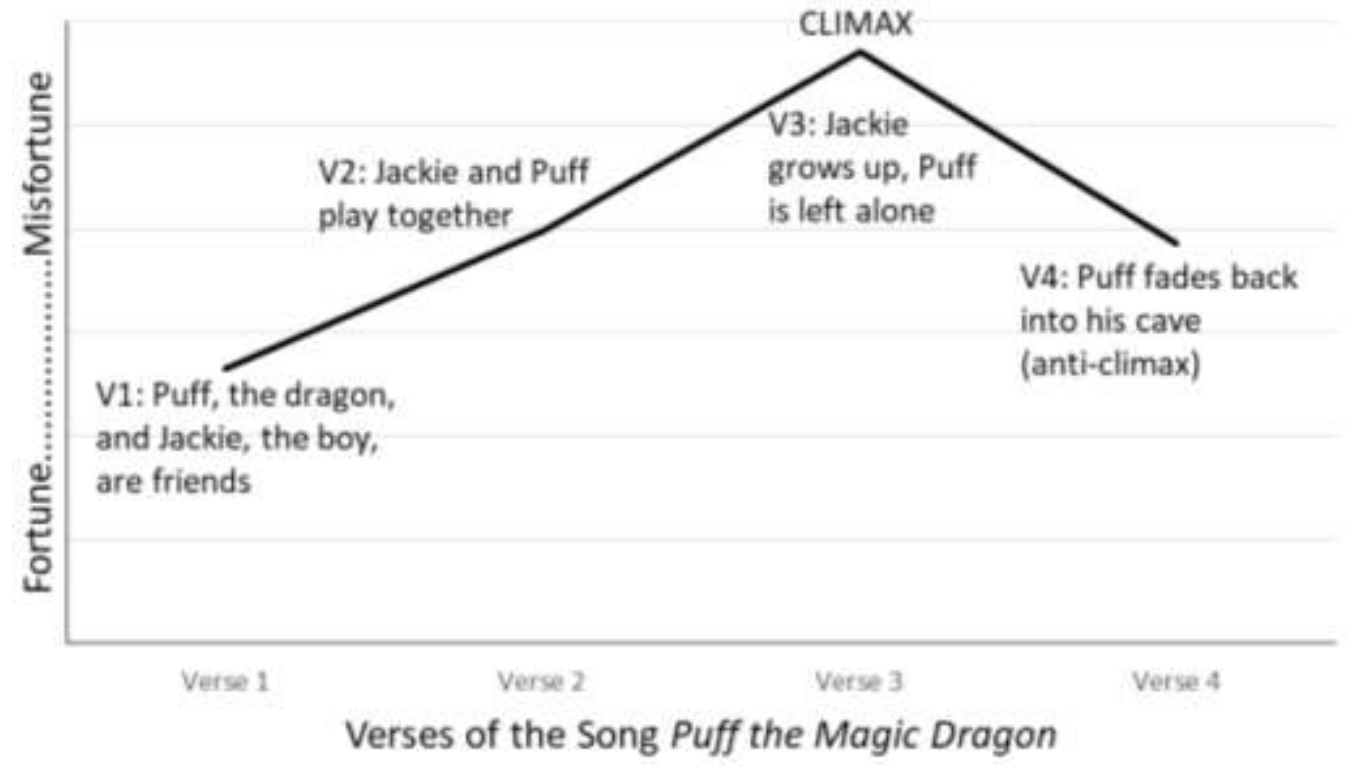

The validity of the Dictionary of Affect is discussed by Whissell (2009). The Dictionary has been used in previous research to outline the plot structures of both novels (Whissell 2018) and poems (Whissell 2017). In the present research the Dictionary will be employed to identify the plot structure of the two ancient Greek epics, with plot structure being defined in terms of variations in unpleasantness or misfortune in the language of each epic over time. The plot structure of the Odyssey and Iliad will then be consulted to answer questions as to their form. Answers will focus on relatively objective data, and will not therefore address issues such as the protagonist's recognition or the motivations underlying characters' behaviors.

\section{Method}

The Dictionary of Affect provides emotional scores only for English words: because of this, it was necessary to study English translations of the epics. The two translations chosen were those of A. S. Kline (Homer 2004, 2009), which have the benefit of having been produced by the same author within a narrow time frame (in the new millennium). Kline's translations employ up-to-date rather than archaic language, and are available on the internet (at the Poetry in Translation website) to researchers wishing to study them.

All words in each translation were matched to the Dictionary of Affect. Matching rates were $87 \%$ for the Odyssey and $82 \%$ for the Iliad. Many of the unmatched words in the Iliad were names. To help address the question of differences among translations, a second translation of the Iliad was also scored with the Dictionary. This translation was downloaded from Project Gutenberg (Homer 1891) and it was considerably older and more archaic in its language than Kline's. 
The Iliad is subdivided into 24 Books. When the pleasantness of Books was correlated across translations, there was evidence of extreme consistency $\left(r_{22}=.95\right.$, $p<.001$ ). Books that included more (or less) pleasant language for one translation also employed more (or less) pleasant language for the other. This suggests that different translators were responding consistently to fluctuations in the emotional connotations of the original. In spite of the consistency of pattern, there was a statistically significant difference between the pleasantness of the Iliad translations (means were 48.50 and $48.12 ; t_{23}=4.88, p<.01, d=1$ ) with Kline's being the more pleasant. This is likely because the alternative translation was produced during the Victorian era, while Kline's translation was contemporary with the Dictionary of Affect, and avoided portentous language.

\section{Results}

\section{Overall Levels of Fortune or Pleasantness}

When all scored words were considered (roughly 94,000 for the Odyssey and 110,000 for the Iliad) there was a difference in the emotional tone of the two epics. The Odyssey was considerably more pleasant or fortunate $(\mathrm{M}=50.40)$ than the Iliad $\left(\mathrm{M}=48.33 ; t_{203,794}=20.23, \mathrm{p}<.001, d=9.4\right)$. The language of the Iliad indicated greater overall misfortune.

\section{Modeled Plots}

The pleasantness of each epic was modeled with a 10-term polynomial regression (Table 3). Prediction was significant in both cases, although effect sizes were small. Such findings suggest that an overall pattern of emotional change has been identified for each poem, but also that there are variations and diversions from this pattern. Modeling reveals the skeletons of the epics, but these skeletons have been fleshed out in complex ways.

Table 3. Standardized Polynomial Regressions Predicting the Pleasantness of the Iliad and the Odyssey from Word Order; All Terms Were Entered Simultaneously

\begin{tabular}{|l|c|c|}
\hline Predictor & B (Iliad) & B (Odyssey) \\
\hline Word order $(\mathrm{O})$ & $-.11^{*}$ & .02 \\
\hline $\mathrm{O}^{2}$ & $.20^{*}$ & $.09^{*}$ \\
\hline $\mathrm{O}^{3}$ & $.29^{*}$ & -.11 \\
\hline $\mathrm{O}^{4}$ & $-.59^{*}$ & $-.42^{*}$ \\
\hline $\mathrm{O}^{5}$ & $-.25^{*}$ & .11 \\
\hline $\mathrm{O}^{6}$ & $.55^{*}$ & $.45^{*}$ \\
\hline $\mathrm{O}^{9}$ & .05 & -.02 \\
\hline $\mathrm{O}^{10}$ & $-.13^{*}$ & $.12^{*}$ \\
\hline $\mathrm{R}$ & .032 & .021 \\
\hline Overall p & $<.001$ & $<.001$ \\
\hline
\end{tabular}

Note: $\mathrm{O}^{7}$ and $\mathrm{O}^{8}$ were excluded from the analysis due to collinearity issues. Source: Author's estimations. 
The plots of the Iliad and the Odyssey are depicted in Figure 2, where scores have been treated as they were in Figure 1.

Figure 2. Plots of the Iliad and the Odyssey Modeled with Polynomial Regressions

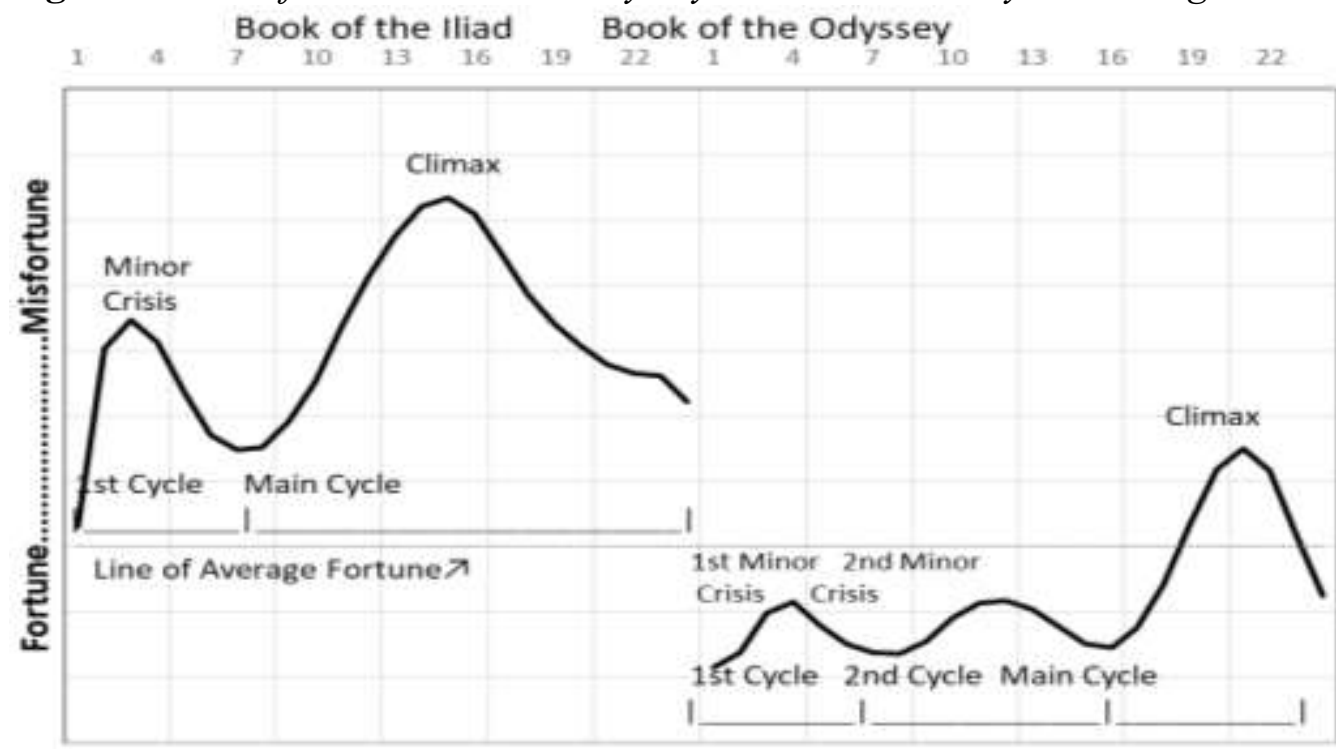

Each point in the graph depicts the unpleasantness of a Book. Low points reflect pleasantness or fortune while high points represent unpleasantness or misfortune. When the line of a plot rises it is moving towards greater misfortune and when it falls toward greater fortune. The climax of each epic, defined as the point of greatest misfortune or unpleasantness, is indicated in the figure. Also appearing in Figure 2 is a faint horizontal dotted line about one third of the way up the vertical axis. This line represents average pleasantness/average fortune (a score of 50) based on samples of more than a third of a million words of everyday English from books, new stories, group discussions, television shows, and other common sources (Whissell 2009). Pleasantness scores greater than 50 (those below the line) characterize texts that would seem pleasant in tone to today's readers, while pleasantness scores less than 50 (those above the line) denote texts that would seem unpleasant. Notably, the plot of the Iliad lies entirely above the average line indicating that it is uniformly unpleasant or unfortunate, while the plot of the Odyssey lies mostly below it indicating that it is mainly pleasant or fortunate in its linguistic tone. Only the climax of the Odyssey rises above the average line and is unfortunate. With few exceptions, all the Books of the Iliad in the modeled plots are more unpleasant than all those of the Odyssey. This is not surprising because the effect size of the difference between poems was extremely strong.

The plot of the Iliad indicates the presence of two cycles - two rises in misfortune followed by returns to greater fortune (Figure 2). Events occurring during the first cycle and the second (main) cycle are described in Table 1. There is a minor high point or crisis in Book 3, while the major crisis of the epic occurs in Book 15. The plot of the Odyssey has three cycles, with the first two being less extreme (they do not rise to any great misfortune). The first 
minor crisis occurs in Book 4 and the second in Book 12. The climax of the epic is in Book 21. The contents of the cycles are described in Table 2.

\section{Overall Movement from Fortune to Misfortune}

One of Aristotle's (1924, XIII) qualifications of good tragedy is that the overall movement of fortune should be from good to bad. This means that language should move towards greater unpleasantness as epics proceed towards their conclusions. When the pleasantness of individual words was correlated with their location in each epic, significant correlations of -.009 and -.013 (df>94,000, $p<.001)$ were noted for the Iliad and Odyssey respectively. These correlations suggest that there is a weak - but statistically significantdrift towards greater unpleasantness as each epic progresses, which satisfies Aristotle's criterion. This drift is probably the result of the unpleasant climaxes which occur later in the poems and it is valid in spite of the fact that in both cases there is a return to greater fortune (an anticlimax) after the climax.

\section{Unity of Plot}

Although Aristotle (1924, XXVII) stressed the importance of the unity of plot in dramatic tragedies, he noted that epics, because of their length, must be allowed to diverge from strict unity or risk becoming uninteresting. The additional cycles of rising and falling fortune appearing in the two epics (Figure 2) would be acceptable in an epic tragedy under this relaxed criterion, so long as the overall unity of theme (the one having to do with Achilles's or Odysseus's problems and actions) is maintained. Although disunity of plot would be an argument against classification of an epic as a tragic one, unity does not necessarily imply tragedy because it can also characterize good comedy.

\section{Activation and Concreteness of Language}

As well as providing scores for the pleasantness of words, the Dictionary of Affect provides scores for their activation or arousal, and for their concreteness. Participants who created the Dictionary were asked to rate how active or aroused (as opposed to quiet or passive) a word's connotations were and also to rate how easy it was to form a mental picture of each word. Easily pictured words were considered concrete and those difficult to picture abstract. Words with active or arousing emotional connotations include battle and fury while those with passive emotional connotations include evening and fatigue. Words such as weapon and ship are concrete while those such as leadership and worry are abstract. Although one can easily understand what leadership and worry are, it is difficult to actually form a concrete picture of these words "in the mind's eye"; this is definitely not the case for ships and weapons, which are easily envisioned. The mean activation of the two epics was compared with a $t$-test. Words in the Iliad were more active than those in the Odyssey (49.95 
vs $\left.49.41, t_{203,794}=5.52, p<.01, d=2.4\right)$. In a parallel comparison, it was noted that words in the Iliad were more concrete and easier to envision than those in the Odyssey (54.41 vs $53.76, t_{203,794}=3.62, p<.01, d=1.6$ ). The Iliad contains many duels, battle scenes, and descriptions of battle accoutrements. This is in contrast to the Odyssey where a good portion of the epic is devoted to a retelling of the protagonist's adventures, usually in a relaxed setting. In a comparison of Shakespeare's tragedies to his comedies, it was noted that tragedies were less pleasant, more active, and more concrete in their language than comedies (Whissell 2007). This pattern of differences also categorized several non-Shakespearean dramas correctly (as tragedies or comedies). The pattern distinguishing the two forms is mirrored exactly in significant differences found between the Iliad and the Odyssey. The former epic (which is almost uniformly considered a tragedy) is less pleasant, more active, and more concrete than the latter (whose classification as a tragedy has been challenged). As well, the combination of greater unpleasantness, greater activation, and greater concreteness chimes with Aristotle's (1924, XXIV) classification of the Iliad as a drama of passion, and the combination of greater pleasantness, greater passivity, and greater abstraction with his classification of the Odyssey as an epic of ethical issues rather than passions.

When the Books of each epic were used as cases, and the pleasantness, activation, and concreteness of each Book as predictors, a discriminant function analysis was able to correctly identify source epic for $92 \%$ of the Books on the basis of the emotionality of their language (canonical correlation $=.77, \mathrm{p}<.001$ ). Concreteness did not contribute significantly to prediction and did not enter the stepwise analysis. According to the standardized canonical discriminant function coefficients (.91 for pleasantness, -.66 for activation), more pleasant and less active Books were assumed to have originated from the Odyssey and less pleasant and more active ones from the Iliad. The one misidentified Book from the Odyssey was Book 22, the one where all the killings take place: due to its unpleasant tone, this Book was misclassified as belonging to the Iliad. The one wrongly attributed Book from the Iliad was Book 24, which was passive in tone and therefore classified as belonging to the Odyssey: this Book deals with Hector's burial. The results of the discriminant function analysis highlight the stability of differences in emotional tone between the epics, which are evident not only in overall means but also in individual Books.

\section{Discussion}

The conclusions outlined below are based strictly upon the quantitative data gathered in the study: they do not address the definition of tragedy in terms of cognitive issues such as hubris and recognition. They are not offered as complete answers to the status of the two epics, but rather as partial answers pointing to issues in their classification. As well, it should be noted that the poems were studied in translation. Even if two translations agree with one another, as was demonstrated earlier, it is possible that neither fully conveys the emotion of the original language. It is, however, unlikely that they are totally independent of it. 
The English translations studied are as close to the emotional meaning of the Ancient Greek originals as their translators could make them.

The quantitative evidence in favor of and against the classification of each Ancient Greek epic as tragic is summarized in Table 4. Evidence supports the conclusion that the Iliad is indeed a tragic epic. It has the right emotional tone of misfortune, and it displays the expected movement towards greater misfortune over time. It is appropriately concrete and active. The Odyssey presents a much more confusing picture. Although it moves towards greater relative misfortune, its overall tone is pleasant and positive, and even though it has an unfortunate climax, its conclusion is firmly in the zone of fortune. As well, the relative passivity and abstraction in its language suggest that it is not tragic in form. The general classification of "comedy" might apply to the Odyssey, but the overall movement towards greater negativity over time speaks against it. Aristotle's (1924, XIII) own classification of the Odyssey as a tragedy turns out to be a guarded one, and he often "excuses" what he considers to be bad plot elements (such as ones where good characters are rewarded and bad ones punished) on the basis of Homer's excellent poetic style. In fact Aristotle goes so far as to call the Odyssey a secondrate tragic epic.

Table 4. Quantitative Evidence that Speaks to the Form (Tragic or Not) of the Iliad and the Odyssey

\begin{tabular}{|l|l|l|}
\hline Epic & $\begin{array}{l}\text { Evidence supporting classification as a } \\
\text { tragedy }\end{array}$ & $\begin{array}{l}\text { Evidence opposing classification } \\
\text { as a tragedy }\end{array}$ \\
\hline Iliad & $\begin{array}{l}\text { Overall tone of misfortune } \\
\text { Conclusion in the zone of misfortune } \\
\text { Overall movement from fortune to misfortune } \\
\text { Presence of a clear unfortunate climax } \\
\text { More active language } \\
\text { More concrete language }\end{array}$ & $\begin{array}{l}\text { Overall movement from greater to lesser fortune } \\
\text { Presence of an unfortunate climax }\end{array}$ \\
\hline Odyssey & $\begin{array}{l}\text { Overall tone of fortune } \\
\text { Conclusion in the zone of fortune } \\
\text { More passive language } \\
\text { More abstract language }\end{array}$ \\
\hline
\end{tabular}

Source: Author's estimations.

The main quantitative difference between epics, and the one that leads directly to problems of classification for the Odyssey, is the overall pleasantness of its words both in comparison to the Iliad and in comparison to everyday English. It is difficult to classify a work as "tragic" when its language unrelentingly promotes positive emotional reactions.

Translator's Comments

A. S. Kline, the translator of the epics studied here, read an earlier version of this paper and provided some additional insights into differences between the Iliad and the Odyssey. He indicated that the epics had "a totally different emotional temperature", 2 which he believed was reflected in his English translations. Describing his reactions to the poems, Kline affirmed that "It is hard to love the Iliad, easier to respect it. But easy to love the Odyssey". Kline

\footnotetext{
${ }^{2}$ All quotations in this section come from a personal communication of April 20, 2018.
} 
also pointed out that the main god of the Iliad was Ares, the God of War, while the main god of the Odyssey was Athena, the Goddess of Wisdom (as well as war). There was also a difference in the loyalty and commitment of the hero to his nation and cause (a factor of enormous importance to the ancient Greeks): Achilles wavered in his commitment and temporarily derailed the Trojan War because of personal issues. Odysseus remained faithful to Penelope and Ithaca. The Iliad therefore tells the story of a less-than-perfectly committed hero (Achilles) whose actions are in the purview of the God of War (Ares) and are described in a less lovable but more highly regarded way in a tragic document with predominantly unpleasant, active, and concrete language. In contrast, the Odyssey tells the tale of a committed hero (Odysseus) whose actions are in the purview of the Goddess of Wisdom (Athena) and are detailed in a more lovable non-tragic document with predominantly pleasant, passive, and abstract language.

\section{References}

Aristotle (1924) Poetics. Translated by SH Butcher. Retrieved from https://bit.ly/1w Va5Lc.

Dean J (1976) The Odyssey as romance. College Literature 3: 288-236.

Hall E (2008) Can the Odyssey ever be tragic? Historical perspectives on the theatrical realization of the Greek epic. In Reverman M, and Wilson P (Eds.), Performance, Iconography, Reception: Studies in Honour of Oliver Taplin. Oxford: Oxford University Press, pp. 499-521.

Homer (2004) The Odyssey. Translated by AS Kline. Retrieved from https://bit.ly/2t210bG.

Homer (1891) The Iliad. Translated by A Lang, W Leaf, and E Myers. Retrieved from https://bit.ly/2CYzYGN.

Homer (2009) The Iliad. Translated by AS Kline. Retrieved from https://bit.ly/2zA90EO.

Martindale C, Tuffin P (1996) If Homer is the poet of the Iliad, then he may not have written the Odyssey. Literary and Linguistic Computing 11: 109-120.

Peter, Paul and Mary (n.d.) Puff (The Magic Dragon). [Lyrics]. Retrieved from https://bit.ly/2sRfr2O.

Rutherford RB (1982) Tragic form and feeling in the Iliad. The Journal of Hellenistic Studies 102: 145-160.

Rutherford RB (1993) From the Iliad to the Odyssey. Bulletin of the Institute of Classical Studies 38: 37-54.

Sutton DF (1974) Satyr plays and the Odyssey. Arethusa 7: 161-185.

Tait M (1943) The tragic philosophy of the Iliad. Transactions and Proceedings of the American Philological Association 74: 49-59.

Whissell C (2007) Quantifying genre: An operational definition of tragedy and comedy based on Shakespeare's plays. Psychological Reports 101: 177-192.

Whissell C (2009) Using the revised Dictionary of Affect in Language to quantify the emotional undertones of samples of natural language. Psychological Reports 105: 1-13.

Whissell C (2017) Event segmentation as an explanation for the seemingly inconsistent structure of Wordsworth's "Prelude". International Journal of Interdisciplinary Cultural Studies 12(1): 23-33.

Whissell C (2018) According to their plots, Jane Austen's novels are not comic romances with happy endings. English Language and Literature Studies 8(2). 
